\title{
Identifying the Chemical Composition Related to the Distinct Aroma Characteristics of New Zealand Sauvignon blanc Wines
}

\author{
Frank Benkwitz, ${ }^{1}$ Takatoshi Tominaga, ${ }^{2}$ Paul A. Kilmartin, ${ }^{1 *}$ Cynthia Lund, ${ }^{3}$ \\ Mark Wohlers, ${ }^{4}$ and Laura Nicolau ${ }^{1}$
}

\begin{abstract}
A comprehensive set of aroma compounds was quantified in 79 Sauvignon blanc wines from different international producers. Emphasis was given to understanding the chemical differences that can explain the unique character of Marlborough Sauvignon blanc. Quantification revealed the potential importance of several volatile compounds in addition to the polyfunctional mercaptans and methoxypyrazines already known to be important to the aroma of Sauvignon blanc wines. Multivariate statistical approaches, including canonical variate analysis, classification tree and partial least square analysis, established correlations between the chemical and the sensory profiles of the wines. A significant role of 3-mercaptohexyl acetate and 3-mercaptohexanol in the unique tropical, fruity character of Marlborough Sauvignon blanc wines was demonstrated, together with important variations in their concentrations, pointing to different styles even within the Marlborough wines.
\end{abstract}

Key words: Sauvignon blanc wine, polyfunctional mercaptans, regions, Marlborough

The distinctive sensory characteristics of Sauvignon blanc wines, such as vegetative, grassy, herbaceous, gooseberry, green pepper, boxwood, grapefruit, and passion fruit, have attracted the attention of several flavor chemists. Over the last three decades, many of the compounds responsible for the distinctive Sauvignon blanc aroma have been identified, including two capsicum-like alkyl-methoxypyrazines (2-methoxy-3isobutylpyrazine [MIBP] and 2-methoxy-3-isopropylpyrazine [MIPP]) (Augustyn et al. 1982, Allen et al. 1991, Lacey et al. 1991, Marais 1994) and three polyfunctional mercaptans (4-mercapto-4-methylpentan-2-one [4MMP], 3-mercaptohexyl acetate [3MHA], and 3-mercaptohexanol [3MH]), also known as varietal thiols, characterized by boxwood, tropical fruit, and grapefruit characters (Tominaga et al. 1998a, 2006). The hypothesis that these compounds are the principal

${ }^{1}$ Wine Science Programme, The University of Auckland, Private Bag 92019, Auckland, New Zealand; ${ }^{2}$ Faculte d'Oenology, Universite Victor Segalen Bordeaux 2, 351 Cours de la Liberation, 33405 Talence Cedex, France; ${ }^{3}$ Horizon Milling, 6405 Rosewood St., Lake Oswego, OR 97035 USA; and ${ }^{4}$ Plant \& Food Research Mt Albert, Private Bag 92169, Auckland 1142, New Zealand.

*Corresponding author (email: p.kilmartin@auckland.ac.nz)

Acknowledgments: This research was funded by contract UOAX0404 from the New Zealand Foundation for Research Science and Technology.

The authors thank the Air New Zealand Wine Awards, Matua Valley Wines, Philip Manson, Andy Frost, and Mike Trought for supplying the wines; Charlotte Foudrier, Amandine Lumineau, Parimal Patel, Robert Winz, Jan Robertson, and Paul Butler for assistance in carrying out the study; Michelle Beresford for help with the sensory analysis; Richard Gardner for comments and suggestions during the study; and Denis Dubourdieu for support of the project. Manuscript submitted Jul 2010, revised Mar 2011, Jul 2011, accepted Sept 2011. Publication costs of this article defrayed in part by page fees.

Copyright $(2012$ by the American Society for Enology and Viticulture. All rights reserved.

doi: 10.5344/ajev.2011.10074 contributors to the aroma of Sauvignon blanc wines is based on their very low perception thresholds resulting in very high odor activity values (OAV: the ratio of concentrations to perception thresholds). However, the wine composition is known to involve numerous additional volatile compounds, and the contribution of fermentative esters, monoterpenes, $\mathrm{C}_{13}$-norisoprenoids, and $\mathrm{C}_{6}$-alcohols to the complexity of Sauvignon blanc wines has been reported or commented upon in the past (Marais et al. 1994, Francis et al. 1992, Sefton et al. 1994). Moreover, over the last two decades a new dimension has been added to flavor chemistry through the use of aroma reconstitution approaches that allow the sensory interactions of chemical compounds to be examined in progressively more complex matrices (Guth 1997, Lee 2003, Ferreira et al. 2006). These approaches have revealed: (1) the importance of low OAV compounds in the overall wine aroma (Escudero et al. $2004),(2)$ the aroma enhancement role of $\beta$-damascenone (Pineau et al. 2007) and dimethyl sulfide (Escudero et al. 2007), and (3) the suppressing effects of certain compounds, such as the alkyl-methoxypyrazines in lowering the tropical fruit impact of 3MHA (Campo et al. 2005), while ethanol also strongly suppresses wine fruitiness (Escudero et al. 2007). These findings stress the need to expand our consideration of the volatile composition of Sauvignon blanc wines to better understand the overall aroma profile of this variety.

Sauvignon blanc is commercially the most important grape variety in New Zealand and accounts for more than $60 \%$ of wine production and for $80 \%$ of wine exports. The main region for Sauvignon blanc production in New Zealand is Marlborough, which produces pungent, intense aromatic wines that blend tropical, passion fruit, sweaty, and stone fruit flavors with capsicum and fresh asparagus notes (Lund et al. 2009a). Early studies found higher concentrations of the capsicumlike, herbaceous MIBP in New Zealand Sauvignon blanc 
wines (Allen et al. 1991, Lacey et al. 1991), which has been confirmed in more recent studies (Parr et al. 2007, Nicolau et al. 2007, Lund et al. 2009a), where the importance of polyfunctional mercaptans has also been recognized. Higher levels of $3 \mathrm{MH}$ and 3MHA in Marlborough wines were established along with good correlations with the tropical passion fruit descriptors, examined using quantitative descriptive analysis (QDA) with a trained sensory panel (Lund et al. 2009a).

The aim of this study was to develop a comprehensive understanding of Sauvignon blanc aroma through the inclusion of more volatile compounds known to contribute to white wine aroma. The emphasis of this study was on the Marlborough region, thus more wines were sampled from this region, together with wines from the Hawkes Bay and Wairarapa regions in New Zealand and from the United States, South Africa, Chile, Australia, and France, all of which produce quality wines of different styles for the international market.

\section{Materials and Methods}

Samples. The study was conducted over two years with commercial wines mainly from two vintages, 2004 and 2005 (Table 1). Since the wines were selected from countries of both hemispheres, there were differences in the date of bottling and the age of the wines at analysis. For both sets of wines, the wines from the southern hemisphere from the 2004 and 2005 vintages were analyzed approximately 14 months after bottling. The wines from the northern hemisphere were analyzed approximately 8 months or 20 months after bottling. The first set of northern hemisphere wines were from the 2004 vintage, except for three wines from France and five wines from the United States, which were from the 2003 vintage. The second set of northern hemisphere wines were from the 2005 vintage, except for two French wines from the 2004 vintage. The wine samples were assessed in triplicate for both chemical and sensory analyses. For the first set of samples, 51 wines were analyzed by sensory and chemical analysis. When sensory analysis was performed, five bottles of wines were sampled for each wine; three were used for sensory analysis and two for chemical analysis. In order to eliminate variation due to the timing of the analysis and bottle-to-bottle variation, the two bottles were opened at once and adequate aliquots were taken for each chemical analysis and kept frozen $\left(-20^{\circ} \mathrm{C}\right)$ for analysis, which were conducted within four months. The chemical

Table 1 Origin and vintage of two sets of commercial wine samples from international regions and three New Zealand regions.

\begin{tabular}{lccccc}
\hline & \multicolumn{2}{c}{ First set } & & \multicolumn{2}{c}{ Second set } \\
\cline { 2 - 3 } \cline { 5 - 6 } Country/region & $\mathbf{2 0 0 3}$ & $\mathbf{2 0 0 4}$ & & $\mathbf{2 0 0 4}$ & $\mathbf{2 0 0 5}$ \\
\hline Australia & & 5 & & 4 \\
Chile & 3 & 2 & & 2 & 1 \\
France & & 6 & & 3 \\
South Africa & 5 & & & 3 \\
United States & & 7 & & 3 \\
Hawkes Bay (NZ) & & 16 & & 9 \\
Marlborough (NZ) & & 7 & & 3 \\
Wairarapa (NZ) & & & &
\end{tabular}

analysis was conducted by category of chemicals, starting with polyfunctional mercaptans, methoxypyrazines, and finishing with the remaining compounds. The triplicate analysis of each sample was conducted on the same day from the same aliquot. The sensory analysis started two months after the beginning of the chemical analyses and was completed within three months.

An additional set of 24 Marlborough commercial Sauvignon blanc wines from the 2007 vintage were quantified for their concentrations of polyfunctional mercaptans approximately eight months after bottling. The retail price of the wines analyzed in this study ranged from US\$6 to $\$ 20$ per bottle, with most of the wines priced between $\$ 8$ and $\$ 14$.

Reagents. All of the chemicals used were of analytical quality. Sodium hydroxide, hydrochloric acid, sodium sulfate, sodium acetate, sodium dihydrogen phosphate dihydrate, and diethyl ether were from Scharlau (Sentmenat, Spain). Dowex Resin $1 \mathrm{X} 2 \mathrm{Cl}^{-}$-form, L-cysteine hydrochloride hydrate, ethyl acetate, and $p$-hydroxymercuribenzoate were from SigmaAldrich (Steinheim, Germany). Hexane was from Burdick \& Jackson (Muskegon, MI), Tris from AppliChem (Darmstadt, Germany), DTNB from Acros Organics (Morris Plains, NJ), ethanol from Ajax Finechem (Taren Point, NSW, Australia), and dichloromethane from Merck (Darmstadt, Germany).

Isoamyl acetate (>98\%) was from Ajax Finechem. Ethyl butanoate (99\%), hexyl acetate (99\%), ethyl octanoate (>99\%), ethyl decanoate (>99\%), diethyl succinate (99\%), 1-hexanol (98\%), phenylethanol (>99\%), 2-methoxy-3-isobutylpyrazine (97\%), 2-methoxy-3-isopropylpyrazine (99\%), linalool (97\%), citronellol (95\%), geraniol (99\%), 3-octanol (>99\%) and 4-methoxy-2-methyl-2-mercaptobutane (99\%) were from Acros Organics. Ethyl hexanoate ( $>98 \%)$, isobutyl acetate $(>99.8 \%)$, ethyl isovalerate (>99.7\%), ethyl isobutyrate (99\%), 3-hexenol $(Z)(98 \%)$, methionol (99\%), 2-hexenol (Z) (95\%), and nerol (97\%) were from Sigma-Aldrich. 3-Hexenol $(E)(97 \%)$, 2-hexenol (E) (97\%), $\alpha$-terpineol (97\%), and 2-methoxy-3methylpyrazine (98\%) were from Lancaster (Ward Mill, MA). Isoamylalcohol (98.5\%) was from Panreac Quimica (Barcelona, Spain). Isobutanol (99.5\%) was from Scharlau. 3-Mercaptohexanol (98\%) and 4-mercapto-4-methylpentan-2-one ( $1 \%$ in polyethylene glycol) were from Interchim (Montluçon, France). 3-Mercaptohexyl acetate (98\%) was from Oxford Chemicals (Billingham, UK).

Quantitative analysis. A specific extraction of wine polyfunctional mercaptans was undertaken according to previous methods (Tominaga et al. 1998b, 2006) from $50 \mathrm{~mL}$ wine. In the first year of study, the thiols were quantified using 4-methoxy-2-methyl-2-mercapto-butane as internal standard. For varietal thiol quantification in the second year, the deuterated analogs of 3-mercaptohexanol (3-mercapto $\left(1-^{2} \mathrm{H}_{2}\right)$ hexanol) and 3 -mercaptohexyl acetate (3-mercapto $\left(1-{ }^{2} \mathrm{H}_{2}\right)$ hexyl acetate) were used as internal standards (Hebditch et al. 2007). Deuterated standards were available only in the second year of the study and helped to improve the method precision (Table 2).

The methoxypyrazines were quantified by liquid-liquid extraction using ether:hexane $(1 / 1, v / v)$ as described elsewhere (Kotseridis et al. 1999) from $200 \mathrm{~mL}$ wine and using 
2-methoxy-3-( $\left({ }^{2} \mathrm{H}_{3}\right)$ isobutylpyrazine instead of 2-methoxy3- $\left({ }^{2} \mathrm{H}_{2}\right)$ isobutylpyrazine as the internal standard. All other compounds, including the esters, alcohols, and monoterpenes, were quantified in the same extract prepared for the methoxypyrazine quantification, using 3-octanol as the internal standard. When the extract from the methoxypyrazine analysis was concentrated to $50 \%$, an aliquot was taken for quantification of esters and further volatile compounds using the chromatographic conditions described by Sabon et al. (2002).

All samples were analyzed with an Agilent $6890 \mathrm{~N}$ gas chromatograph (Santa Clara, CA) and a 5973 mass selective detector. The MS was in EI mode, with EMV at $1953 \mathrm{~V}$, the source at $230^{\circ} \mathrm{C}$, the quad at $150^{\circ} \mathrm{C}$, emission at $34.6 \mu \mathrm{A}$, and the Ele energy at $69.9 \mathrm{eV}$. The capillary columns were BP20 (SGE Analytical Science, Ringwood, Australia) (50 m x $220 \mu \mathrm{m} \times 0.25 \mu \mathrm{m}$ ) for the first set of samples analyzed and HP-INNOWax (Agilent) $(60 \mathrm{~m} \times 252 \mu \mathrm{m} \times 0.25 \mu \mathrm{m})$ for the second set of samples. All of the compounds were identified based on the retention times of reference compounds. Linear retention indices on the capillary columns agreed with those given in the literature for a $\mathrm{C} 20 \mathrm{M}$ column with similar properties (www.flavornet.com).

Calibrations were carried out in all cases using the standard addition method. A wine sample was extracted together

Table 2 Linearity, quantification data, perception thresholds, and descriptors for the volatile compounds analyzed in this study.

\begin{tabular}{|c|c|c|c|c|c|c|}
\hline Compound & $\begin{array}{c}\text { Correlation } \\
\text { coefficient } \\
\left(r^{2}\right)\end{array}$ & $\begin{array}{c}\text { Calibration } \\
\text { range } \\
(\mu \mathrm{g} / \mathrm{L})\end{array}$ & $\begin{array}{c}\text { Recovery } \\
\text { in calibration } \\
\text { range (\%) }\end{array}$ & $\begin{array}{c}\text { Average relative } \\
\text { standard } \\
\text { deviation (\%) }\end{array}$ & $\begin{array}{c}\text { Perception } \\
\text { threshold } \\
(\mu \mathrm{g} / \mathrm{L})\end{array}$ & Descriptors \\
\hline \multicolumn{7}{|l|}{ Esters } \\
\hline Isoamyl acetate ${ }^{a}$ & 0.998 & 1194-3980 & $96-104$ & 4.3 & 50 & Banana, fruity \\
\hline Hexyl acetate & 0.995 & $52-870$ & $90-107$ & 3.8 & 400 & Apple, cherry, pear, flower \\
\hline Ethyl butanoate ${ }^{b}$ & 0.999 & $96-960$ & $93-109$ & 6.2 & 20 & Fruity, apple \\
\hline Ethyl hexanoate ${ }^{a}$ & 0.996 & $212-1414$ & $96-113$ & 3.4 & 45 & Apple peel, fruit \\
\hline Ethyl octanoatec & 0.997 & $684-2851$ & $93-104$ & 3.9 & 600 & Sweet, ripe banana, pear \\
\hline Ethyl decanoated & 0.995 & 92-920 & $94-116$ & 5.2 & 200 & Fruity, floral \\
\hline Diethyl succinate ${ }^{c}$ & 0.999 & $137-911$ & $98-107$ & 3.8 & 1250000 & Fruit \\
\hline Isobutyl acetate & 0.982 & $12-119$ & $91-122$ & 6.8 & 1605 & Fruit, apple, banana \\
\hline Ethyl isovalerate ${ }^{d}$ & 0.996 & $3.6-109$ & $95-112$ & 5.8 & 3 & Fruit \\
\hline Ethyl isobutyrate ${ }^{b}$ & 0.995 & $10-167$ & $93-106$ & 9.0 & 15 & Sweet, rubber \\
\hline \multicolumn{7}{|l|}{ Alcohols } \\
\hline 1-Hexanolg & 0.982 & $342-5693$ & $94-108$ & 3.6 & 1110 & Resin, flower, green, cut grass \\
\hline 3-Hexenol $(E)^{\mathrm{c}}$ & 0.993 & $11-112$ & $91-117$ & 3.9 & 1000 & Green, cut grass \\
\hline 3-Hexenol $(Z)^{\mathrm{b}}$ & 0.993 & $50-841$ & $87-114$ & 3.5 & 400 & Green, cut grass \\
\hline Phenylethanol ${ }^{d}$ & 0.999 & $13900-46330$ & $98-104$ & 4.8 & 14000 & Honey, spice, rose, lilac \\
\hline Isoamylalcoholb & 0.989 & $29700-148300$ & $83-110$ & 5.2 & 30000 & Whiskey, malt, burnt \\
\hline Isobutanol ${ }^{b}$ & 0.987 & $4000-36030$ & $92-112$ & 8.0 & 40000 & Wine, solvent, bitter \\
\hline Methionolb & 0.994 & 157-2624 & $90-111$ & 3.6 & 500 & Sweet, potato \\
\hline 2-Hexenol $(E)^{g}$ & 0.998 & $0.55-7.8$ & $83-105$ & 12.6 & - & Green, cut grass \\
\hline 2-Hexenol $(Z)^{\mathrm{g}}$ & 0.999 & $1.3-58.1$ & $90-102$ & 8.2 & - & Green, cut grass \\
\hline \multicolumn{7}{|l|}{ Monoterpenes } \\
\hline Linaloold,g & 1 & $5.09-15.9$ & $99-100$ & 5.4 & 25.2 & Fruity, citrus, floral, lavender \\
\hline Terpineolg,l & 0.998 & $2.93-19.1$ & $96-111$ & 3.9 & 250 & Floral, sweet \\
\hline Citronellol $\mathrm{l}_{\mathrm{f}, \mathrm{g}}$ & 0.999 & $0.66-2.2$ & $99-100$ & 4.6 & 100 & Rose \\
\hline Nerolg & 0.999 & $0.7-2.35$ & - & - & - & Fruity, floral, sweet \\
\hline Geraniolo $^{\mathrm{b}, \mathrm{g}}$ & 0.999 & $0.82-2.75$ & $99-101$ & 5.1 & 300 & Rose, geranium \\
\hline \multicolumn{7}{|l|}{ Thiols } \\
\hline 3-Mercaptohexanol ${ }^{\mathrm{h}}$ & 0.998 & $0.458-10.98$ & $90-105$ & $5.1(13.1)^{\mathrm{k}}$ & 0.06 & Grapefruit, passion fruit \\
\hline 3-Mercaptohexyl acetate ${ }^{h}$ & 0.999 & $0.052-1.678$ & $95-106$ & $7.1(15.3)^{\mathrm{k}}$ & 0.004 & Passion fruit, box tree \\
\hline 4-Mercapto-4-methylpentan-2-one & 0.999 & $0.0054-0.172$ & $97-104$ & 9.4 & 0.0008 & Box tree, broom, cat urine \\
\hline \multirow{2}{*}{$\begin{array}{l}\text { Methoxypyrazines } \\
\text { 2-Methoxy-3-isobutylpyrazine } \\
\text { 2-Methoxy-3-isopropylpyrazine }\end{array}$} & & $0.0045-0.072$ & $94-104$ & & 0.002 & Green pepper \\
\hline & 0.999 & $0.0046-0.074$ & $98-108$ & $\begin{array}{l}0.5 \\
4.8\end{array}$ & 0.002 & Green pepper, earthy \\
\hline
\end{tabular}

a12.5\% (v/v) ethanol, $\mathrm{pH} 3.2$.

b10\% (w/w) ethanol (Guth 1997).

${ }^{c} 14 \%(\mathrm{v} / \mathrm{v}$ ) ethanol, pH 3.5 (Moyano et al. 2002).

$\mathrm{d} 10 \%(\mathrm{v} / \mathrm{v}$ ) ethanol, $\mathrm{pH} 3.2$ (Ferreira et al. 2000).

e10\% (v/v) ethanol, pH 3.2 (Ferreira et al. 2002).

${ }^{\mathrm{f}} 10 \%$ (v/v) ethanol, pH 3.5 (Peinado et al. 2006).

gQuantified only in the first year of the study.

${ }^{\mathrm{h}} 12 \%$ (v/v) ethanol (Tominaga et al. 1998a).

'White wine (Allen et al. 1991).

Water (Seifert et al. 1970); average relative standard deviation (\%)

kAverage of 49 triplicates, first year using 4-methoxy-2-methyl-2-mercaptobutane as internal standard.

'Media unknown (Rychlik et al. 1998). 
with increasing concentrations of the compounds to be quantified. Peak areas for the analytes and internal standards were integrated and the peak areas of the analytes were divided by the peak areas of the corresponding internal standard. The ratio from the blank wine was then subtracted from the ratios of the samples containing increasing amounts of the aroma compounds. Linear regression was used to obtain the function to calculate the concentration of the analytes in the samples. The values (Table 2) were obtained during method evaluations undertaken in the second year of analysis, with the exception of a few compounds that were only quantified in the first study year. $\mathrm{R}^{2}$ values, recovery, and average relative standard deviations (RSD) were very similar for the analyses in both years, except for $3 \mathrm{MH}$ and $3 \mathrm{MHA}$ where the quantification precision improved in the second year of quantification, from 13.1 and 15.3 average \%RSD, to 5.1 and 7.1 average \%RSD, respectively, due to the use of labeled standards.

Sensory analysis. Descriptive analysis of the wines was carried out under previously described conditions (Lund et al. 2009a). Trained panelists evaluated 51 wines in triplicate under an incomplete randomized block design. The panelists were given the samples randomly and the randomized samples were blocked by replication $(1,2,3)$. The panelists evaluated 10 to 11 wines per session, with a 30 -sec break after each wine and a 5-min break after every three wines. Each panelist returned for 15 sessions so that each one tasted every wine. Variations were made to the presentation order of the wine samples served concurrently to all panelists and to the presentation order of subsequent replicate samples provided to individual panelists. The panelists rated the intensities of 16 attributes on a computer using Compusense software (version 5.0, Guelph, Canada). The attributes and their associated reference standards are listed (Table 3).

Statistical analysis. Microsoft Excel 2007 software was used for basic data analysis and generation of boxplots. For the identification of regional differences in the levels of aroma compounds, one-way ANOVA was carried out in SAS 9.2 (SAS Institute, Cary, NC) with all pair-wise comparisons adjusted for multiple comparisons using Tukey's HSD at the $95 \%$ confidence level. For a multivariate examination of the data, canonical variate analysis (CVA) was used and a classification tree was fitted in Genstat 10 and used the Ginni Information Criterion to select the variate to split the data at each node. A minimum number of five observations in each group were specified to stop the splitting process. Partial least squares regression (PLS) was performed (Unscrambler version 9.1, CAMO, Oslo, Norway) to determine relationships among the chemical and sensory data.

\section{Results}

Quantifications are given for the first set (2003 and 2004 vintages; Table 4) and second set (2004 and 2005 vintages; Table 5) of wines, summarized as the mean and standard deviation values for each region and country. One-way analysis of variance (ANOVA) was used as a test for the difference in the means of each chemical ( $p$ value). When the overall $p$ value was significant, pair-wise comparisons were adjusted for multiple comparisons using Tukey's HSD at the 95\% confidence level to compare the regions with protection against false positives due to multiple testing.

Some additional esters - ethyl hexanoate, ethyl isovalerate, ethyl isobutyrate, diethyl succinate, and isobutyl acetatewere included in the second year (Table 5) following GCMS and GC/O screening (Nicolau et al. 2008). Most esters quantified in this study had concentration ranges similar to those reported for other white varieties (Guth 1997, Ferreira 1993), except for a few compounds with higher (including ethyl hexanoate and ethyl isovalerate) or lower (such as ethyl isobutyrate) concentrations. As indicated by the $p$ values and the pair-wise comparison tests (Table 4), in the first set of

\begin{tabular}{|c|c|}
\hline Lexicon & Reference standard \\
\hline Sweet sweaty passion fruit & 2,000 ng/L 3-mercaptohexyl acetate (Oxford Chemicals) ${ }^{a}$ \\
\hline Capsicum & 1,000 ng/L 2-methoxy-3-isobutylpyrazine (Acros Organics) ${ }^{a}$ \\
\hline Cat urine/box wood & 1,000 ng/L 4-mercapto-4-methylpentan-2-one (Oxford Chemicals) ${ }^{a}$ \\
\hline Passion fruit skin/stalk & 2,000 ng/L 3-mercaptohexan-1-ol (Interchim) ${ }^{a}$ \\
\hline Grassy & $28,800 \mathrm{ng} / \mathrm{L} 2$-hexenol $(Z)(\text { Sigma })^{\mathrm{a}}$ \\
\hline Flint/mineral & $4,000 \mathrm{ng} / \mathrm{L}$ benzyl methyl thiol (Oxford Chemicals) ${ }^{\mathrm{a}}$ \\
\hline Citrus & $30 \mathrm{~g}$ Yen Ben lemon plus $15 \mathrm{~g}$ Bear lime soaked in diluted base wine for 30 min $^{\mathrm{b}}$ \\
\hline Bourbon & $2,400 \mu \mathrm{g} / \mathrm{L}$ hexanol $(\text { Sigma })^{a}$ \\
\hline Apple lolly/candy & $2,500 \mu \mathrm{g} / \mathrm{L}$ hexyl acetate $(\text { Sigma })^{\mathrm{a}}$ \\
\hline Tropical & $\begin{array}{l}40 \mathrm{~mL} \text { Golden Circle Mango juice }+40 \mathrm{~mL} \text { Golden Circle Golden Pash }+200 \mathrm{~mL} \\
\text { Just Juice Mandarin Passion Fruit juice }\end{array}$ \\
\hline Mint & $25 \mathrm{mg} / \mathrm{L}$ cineole $(\text { Sigma })^{\mathrm{a}}$ \\
\hline Fresh asparagus & $50 \mathrm{~mL}$ steamed asparagus water ${ }^{\mathrm{b}}$ \\
\hline Canned asparagus & $10 \mathrm{~mL}$ Watties canned asparagus juice ${ }^{b}$ \\
\hline Stone fruit & Canned Watties apricot and peach juice soaked in diluted base wine for 30 min (equal parts) \\
\hline Apple & $70 \mathrm{~g}$ Sciros/Pacific Rose apple peeled, soaked in diluted base wine for $30 \mathrm{~min}^{\mathrm{b}}$ \\
\hline Snow pea & 1,275 ng/L 2-methoxy-3-methylpyrazine (Acros Organics) ${ }^{a}$ \\
\hline
\end{tabular}

aAdded to the diluted base wine (50\% Corbans Sauvignon blanc and $50 \%$ water).

${ }^{\mathrm{b}}$ Added in equal parts to the base wine (Corbans Sauvignon blanc). 
samples most esters were significantly higher in the three New Zealand wine regions than in the international wines, but this difference was not repeated with the second set of samples (Table 5). Significant differences between the regions and countries and for both sets of samples were also observed in the mean levels of the higher alcohols.

The monoterpenes were quantified only in the first set of samples, and the levels agreed with those previously reported for Sauvignon blanc wines (Ribéreau-Gayon 2001). Significant differences were observed between regions and countries, except for terpineol (Table 4).

More evident differences between the regions and countries were observed for the varietal $\mathrm{C}_{6}$-alcohols, methoxypyrazines, and polyfunctional mercaptans. Among the $\mathrm{C}_{6}$ alcohols, 3-hexenol (Z) stood out with significantly higher concentrations in wines from the Marlborough region, followed closely by wines from other New Zealand regions and Australia. 2-Methoxy-3-isobutylpyrazine (MIBP) and 2-methoxy-3-isopropylpyrazine (MIPP) were quantified in the first set of samples (Table 3). The mean values for MIPP were slightly higher than for concentrations previously reported in Sauvignon blanc wines (Lacey et al. 1991). Minor but significant differences were observed between the regions and countries, notably significantly higher mean levels in the Australian wines. As previously demonstrated (Lund et al. 2009a), the New Zealand wines, and especially those from the Wairarapa and Marlborough, were significantly higher in MIBP than the wines from other countries, in agreement with previous studies (Lacey et al. 1991). Due to an instrumental fault at the time of running the second set of samples, only MIBP was quantified (Table 5). The mean level for the Marlborough wines was very close to that obtained for the previous set of samples, but the mean level for the Wairarapa wines was lower. The missing data for some Hawkes Bay, Australia, and French wines made the MIBP data insufficient for statistical analyses.

The polyfunctional mercaptans $3 \mathrm{MH}, 3 \mathrm{MHA}$, and 4MMP are important impact odorants in Sauvignon blanc wines, and the quantitative data obtained in this study were consistent with concentrations reported previously (Tominaga et al. 1998a). For 3MHA, the mean concentration for Marlborough wines was significantly higher than that of all other regions and countries for the first set of samples (Table 4). The second set was similar (Table 5), with the exception of the Chilean and United States means, which were not significantly different than the Marlborough values. Likewise, for $3 \mathrm{MH}$ with the first set of samples (Table 4), the mean concentration in the Marlborough wines was significantly higher than that of all of the other regions and countries except Wairarapa. However, in the second set of samples, $3 \mathrm{MH}$ mean for the Marlborough wines was only significantly different than the Australian, French, and United States mean (Table 5). In the first set of

Table 4 Average concentrations, standard deviations, and ANOVA $p$ values for the volatile compounds quantified in the first set of samples (2003 and 2004 vintages).

\begin{tabular}{|c|c|c|c|c|c|c|c|c|}
\hline & $\begin{array}{l}\text { Marlborough } \\
\text { (NZ) } n=7\end{array}$ & $\begin{array}{l}\text { Hawkes Bay } \\
\text { (NZ) } n=7\end{array}$ & $\begin{array}{l}\text { Wairarapaw } \\
(\mathrm{NZ}) \mathrm{n}=7\end{array}$ & $\begin{array}{c}\text { Australia }^{a} \\
n=5\end{array}$ & $\begin{array}{c}\text { South Africas } \\
n=6\end{array}$ & $\begin{array}{c}\text { France }^{f} \\
n=5\end{array}$ & $\begin{array}{l}\text { USA }^{u} \\
\mathrm{n}=5\end{array}$ & $\begin{array}{c}p \\
\text { value }\end{array}$ \\
\hline \multicolumn{9}{|l|}{ Esters } \\
\hline Ethyl butanoate $(\mu \mathrm{g} / \mathrm{L})$ & $548 \pm 99^{f *}$ & $576 \pm 100^{f}$ & $510 \pm 89$ & $381 \pm 81^{u}$ & $480 \pm 154$ & $378 \pm 122^{g}$ & $680 \pm 446$ & 0.0599 \\
\hline Ethyl octanoate $(\mu \mathrm{g} / \mathrm{L})$ & $1371 \pm 479^{\mathrm{s}, \mathrm{u}}$ & $1455 \pm 516^{\mathrm{s}, \mathrm{u}}$ & $1631 \pm 359^{\mathrm{a}, \mathrm{s}, \mathrm{u}}$ & $1116 \pm 211$ & $864 \pm 367$ & $1265 \pm 562$ & $790 \pm 98$ & 0.0092 \\
\hline Ethyl decanoate $(\mu \mathrm{g} / \mathrm{L})$ & $368 \pm 197^{u}$ & $362 \pm 221^{u}$ & $464 \pm 213^{\mathrm{a}, \mathrm{s}, \mathrm{f}, \mathrm{u}}$ & $271 \pm 140$ & $194 \pm 228$ & $227 \pm 148$ & $78 \pm 12$ & 0.0165 \\
\hline Isoamyl acetate $(\mu \mathrm{g} / \mathrm{L})$ & $2531 \pm 670^{\mathrm{a}, \mathrm{s}, \mathrm{f}, \mathrm{u}}$ & $2515 \pm 963^{\mathrm{a}, \mathrm{f}, \mathrm{u}}$ & $2892 \pm 962^{\mathrm{a}, \mathrm{s}, \mathrm{f}, \mathrm{u}}$ & $1430 \pm 371$ & $1732 \pm 773$ & $1547 \pm 805$ & $999 \pm 345$ & 0.0001 \\
\hline Hexyl acetate $(\mu \mathrm{g} / \mathrm{L})$ & $196 \pm 71^{\mathrm{a}, \mathrm{s}, \mathrm{f}, \mathrm{u}}$ & $174 \pm 117^{\mathrm{a}, \mathrm{s}, \mathrm{f}, \mathrm{u}}$ & $148 \pm 32^{\mathrm{s}, \mathrm{f}, \mathrm{u}}$ & $88 \pm 20$ & $56 \pm 37$ & $43 \pm 27$ & $43 \pm 31$ & $<.0001$ \\
\hline \multicolumn{9}{|l|}{ Alcohols } \\
\hline 1-Hexanol $(\mu \mathrm{g} / \mathrm{L})$ & $3081 \pm 617^{\mathrm{s}, \mathrm{f}}$ & $2901 \pm 903^{s, f}$ & $3105 \pm 536^{s, f}$ & $2710 \pm 602^{s, f}$ & $1672 \pm 440^{u}$ & $1732 \pm 942^{u}$ & $2872 \pm 1190$ & 0.0009 \\
\hline 3-Hexenol $(E)(\mu \mathrm{g} / \mathrm{L})$ & $98 \pm 16^{a}$ & $69 \pm 22^{a}$ & $94 \pm 26^{a}$ & $175 \pm 90^{\mathrm{s}, \mathrm{f}, \mathrm{u}}$ & $98 \pm 37$ & $102 \pm 85$ & $95 \pm 65$ & 0.0235 \\
\hline 3-Hexenol $(Z)(\mu \mathrm{g} / \mathrm{L})$ & $599 \pm 179^{w, a, s, f, u}$ & $528 \pm 159^{\mathrm{s}, \mathrm{f}, \mathrm{u}}$ & $417 \pm 91^{\mathrm{s}, \mathrm{f}, \mathrm{u}}$ & $420 \pm 95^{\mathrm{f}, \mathrm{u}}$ & $260 \pm 99$ & $197 \pm 84$ & $227 \pm 46$ & $<.0001$ \\
\hline 2-Hexenol $(E)(\mu \mathrm{g} / \mathrm{L})$ & $2.8 \pm 2.6^{s}$ & $2.9 \pm 2.1$ & $2.7 \pm 1.3$ & $4.5 \pm 4.1^{\mathrm{s}, \mathrm{u}}$ & $0.5 \pm 0.8^{f}$ & $4.4 \pm 3^{u}$ & $1.1 \pm 1.0$ & 0.0329 \\
\hline 2-Hexenol $(Z)(\mu \mathrm{g} / \mathrm{L})$ & $12 \pm 3^{\mathrm{h}}$ & $22 \pm 9.8^{w, a, s, f, u}$ & $15 \pm 3$ & $15 \pm 5$ & $10 \pm 5$ & $15 \pm 5$ & $15 \pm 6$ & 0.0022 \\
\hline Phenylethanol (mg/L) & $38 \pm 16^{\mathrm{a}, \mathrm{s}, \mathrm{u}}$ & $33 \pm 11$ & $43 \pm 14^{\mathrm{a}, \mathrm{s}, \mathrm{u}}$ & $22 \pm 10^{f}$ & $17 \pm 4^{f}$ & $46 \pm 30^{u}$ & $19 \pm 8$ & 0.0038 \\
\hline \multicolumn{9}{|l|}{ Monoterpenes } \\
\hline Linalool ( $\mu \mathrm{g} / \mathrm{L})$ & $12 \pm 4.2^{\mathrm{w}, \mathrm{s}}$ & $12 \pm 3^{s}$ & $15 \pm 4^{\mathrm{a}, \mathrm{s}, \mathrm{u}}$ & $9.8 \pm 3.8$ & $7.0 \pm 3.1^{f}$ & $13 \pm 6$ & $8.8 \pm 2.2$ & 0.005 \\
\hline Terpineol ( $\mu \mathrm{g} / \mathrm{L})$ & $19 \pm 6$ & $18 \pm 3$ & $18 \pm 5$ & $21 \pm 7$ & $15 \pm 5$ & $19 \pm 9$ & $14 \pm 4$ & 0.3666 \\
\hline Citronellol ( $\mu \mathrm{g} / \mathrm{L})$ & $2.6 \pm 0.7^{s, f}$ & $2.5 \pm 0.4^{f}$ & $2.3 \pm 0.7$ & $2.1 \pm 0.6$ & $1.8 \pm 0.5^{u}$ & $1.7 \pm 0.4^{u}$ & $2.6 \pm 0.7$ & 0.0282 \\
\hline Geraniol ( $\mu \mathrm{g} / \mathrm{L})$ & $2.0 \pm 0.8^{s}$ & $2.2 \pm 0.7^{\mathrm{s}}$ & $2.8 \pm 0.9^{\mathrm{a}, \mathrm{s}, \mathrm{u}}$ & $1.6 \pm 1.1$ & $1.0 \pm 0.4^{f}$ & $2.3 \pm 1.7^{u}$ & $1.3 \pm 0.5$ & 0.0061 \\
\hline \multicolumn{9}{|l|}{ Thiols } \\
\hline 3MHA (ng/L) & $516 \pm 572^{\mathrm{h}, \mathrm{w}, \mathrm{a}, \mathrm{s}, \mathrm{f}, \mathrm{u}}$ & $65 \pm 45$ & $99 \pm 121$ & $68 \pm 10$ & $38 \pm 23$ & $29 \pm 34$ & $45 \pm 18$ & 0.0001 \\
\hline $3 \mathrm{MH}(\mathrm{ng} / \mathrm{L})$ & $7080 \pm 5567^{\mathrm{h}, \mathrm{a}, \mathrm{s}, \mathrm{f}, \mathrm{u}}$ & $1733 \pm 765^{w}$ & $5219 \pm 5316^{s}$ & $2379 \pm 1664$ & $1526 \pm 376$ & $2050 \pm 869$ & $2094 \pm 1628$ & 0.0006 \\
\hline 4MMP (ng/L) & $8.2 \pm 3.4$ & $9.0 \pm 5.1$ & $19 \pm 9^{\mathrm{a}, \mathrm{s}, \mathrm{u}}$ & $5.5 \pm 2.7$ & $6.6 \pm 1.5$ & $9.7 \pm 4.5$ & $5.7 \pm 2.1$ & 0.003 \\
\hline \multicolumn{9}{|l|}{ Methoxypyrazines } \\
\hline MIBP (ng/L) & $22 \pm 7^{\mathrm{w}, \mathrm{a}, \mathrm{s}, \mathrm{f}, \mathrm{u}}$ & $17 \pm 9.4^{\mathrm{w}, \mathrm{f}, \mathrm{u}}$ & $35 \pm 9^{\mathrm{a}, \mathrm{s}, \mathrm{f}, \mathrm{f}, \mathrm{u}}$ & $14 \pm 4^{u}$ & $14 \pm 11^{u}$ & $7.9 \pm 4.2$ & $4.6 \pm 2.4$ & 0.003 \\
\hline MIPP (ng/L) & $8.4 \pm 1.8^{\mathrm{h}, \mathrm{a}}$ & $7.4 \pm 0.8^{w, a}$ & $9.5 \pm 1.7^{\mathrm{a}, \mathrm{s}, \mathrm{u}}$ & $13 \pm 3^{s, f, u}$ & $7.9 \pm 1.2$ & $8.1 \pm 2.6$ & $7.8 \pm 0.7$ & $<.0001$ \\
\hline
\end{tabular}

${ }^{*}$ Superscript letters $\left({ }^{m}=\right.$ Marlborough, ${ }^{\mathrm{h}}=$ Hawkes Bay, ${ }^{\mathrm{w}}=$ Wairarapa, ${ }^{\mathrm{a}}=$ Australia, ${ }^{\mathrm{s}}=$ South Africa, ${ }^{\mathrm{f}}=$ France, ${ }^{\mathrm{u}}=$ United States) indicates the significant differences between countries and regions obtained using a pair-wise comparison (Tukey's HSD) with 95\% level of confidence. 
samples, the 4MMP mean (Table 4) of the Wairarapa wines was significantly higher than the mean for the Australian, South African, and United States wines. In the second set of samples, despite higher means obtained again for the Wairarapa and United States wines, no significant differences in 4MMP concentrations were observed (Table 5).

The differences among regions and countries in the second set of samples were not as great as in the first set, especially regarding the esters. The lack of significant differences observed with the second set can be explained by the low number of samples quantified, as only three wines were analyzed for most of the countries and regions, except for Australia with four wines and Marlborough with nine wines, which made this set of data not suitable for further statistical investigation. Moreover, in the first set of samples, $3 \mathrm{MH}$ and 3MHA concentrations in some of the Marlborough wines were particularly high and were also characterized by a greater variation within the region (Figure 1). However, with the second set of samples, the average $3 \mathrm{MH}$ and $3 \mathrm{MHA}$ concentrations were lower and the variation was not so extreme. As the 2006 Marlborough vintage had the earliest harvest dates on record, the testing of the additional Marlborough Sauvignon blanc wines from the 2007 vintage was important to confirm that the high $3 \mathrm{MH}$ and $3 \mathrm{MHA}$ concentrations obtained in the first set of wines were not accidental. The results for $3 \mathrm{MH}$ and 3MHA for these extra 2007 wines (Figure 2) were closer to those obtained for the 17 wines from the first set of wines (2004 vintage) than for the nine wines from the second set (2005 vintage). Moreover, the wide Marlborough within-region variation observed for the 2004 vintage wines was confirmed in this larger sample set. The 4MMP concentrations obtained for the 2007 vintage Marlborough wines ranged from 6.2 to $19.5 \mathrm{ng} / \mathrm{L}$ (data not shown).

The higher number of samples (51 wines) analyzed for the first data set allowed the application of multivariate statistical analysis for the identification of regional differences. Canonical variate analysis (CVA) was chosen for its ability to maximize differences between groups. A CVA plot was obtained using concentrations of aroma compounds and regions as variables (Figure 3). The ellipses represent the $95 \%$ confidence intervals for the means of the regions. Fifty percent of the differences in this data set can be explained by the first two dimensions. The first dimension explains $26 \%$ of the difference and separates the three New Zealand regions from the other countries (Figure 3A), which was due to their higher concentrations of 3-hexenol $(Z)$, hexyl acetate, isoamyl acetate, 3MH, 3MHA, 1-hexanol, ethyl octanoate, and ethyl decanoate. In the second dimension, Wairarapa was separated from the other two New Zealand regions by higher levels of 4MMP, MIBP, and the two terpenes linalool and geraniol. The 95\% confidence intervals for the Australian and South African wines overlap. Australia, South Africa, and United

Table 5 Average concentrations, standard deviations, and ANOVA $p$ values for the volatile compounds quantified in second set of samples (2004 and 2005 vintages).

\begin{tabular}{|c|c|c|c|c|c|c|c|c|}
\hline & $\begin{array}{l}\text { Marlborough }^{\mathrm{m}} \\
(\mathrm{NZ}) \mathrm{n}=\mathbf{9}\end{array}$ & $\begin{array}{c}\text { Hawkes Bay } \\
\text { (NZ) } n=3\end{array}$ & $\begin{array}{c}\text { Wairarapaw } \\
\text { (NZ) } n=3\end{array}$ & $\begin{array}{c}\text { Australia }^{a} \\
n=4\end{array}$ & $\begin{array}{c}C^{C h i l e} \\
\mathrm{n}=3\end{array}$ & $\begin{array}{c}\text { France }^{f} \\
n=3\end{array}$ & $\begin{array}{l}\text { USA }^{u} \\
n=3\end{array}$ & $\begin{array}{c}p \\
\text { value }\end{array}$ \\
\hline \multicolumn{9}{|l|}{ Esters } \\
\hline Ethyl butanoate $(\mu \mathrm{g} / \mathrm{L})$ & $337 \pm 102^{w, a, u *}$ & $441 \pm 83$ & $487 \pm 89$ & $462 \pm 132$ & $451 \pm 69$ & $359 \pm 34^{u}$ & $530 \pm 89$ & 0.045 \\
\hline Ethyl hexanoate $(\mu \mathrm{g} / \mathrm{L})$ & $1168 \pm 1491$ & $1137 \pm 122$ & $1330 \pm 124$ & $1248 \pm 242$ & $1250 \pm 150$ & $1042 \pm 111$ & $1155 \pm 214$ & 0.436 \\
\hline Ethyl octanoate $(\mu \mathrm{g} / \mathrm{L})$ & $1697 \pm 394$ & $1695 \pm 333$ & $2505 \pm 926$ & $1950 \pm 296$ & $1650 \pm 263$ & $1629 \pm 59$ & $1578 \pm 262$ & 0.118 \\
\hline Ethyl decanoate $(\mu \mathrm{g} / \mathrm{L})$ & $581 \pm 166$ & $574 \pm 309$ & $608 \pm 164$ & $497 \pm 292$ & $450 \pm 80$ & $416 \pm 80$ & $435 \pm 27$ & 0.669 \\
\hline Ethyl isobutyrate $(\mu \mathrm{g} / \mathrm{L})$ & $69 \pm 27$ & $96 \pm 41$ & $105 \pm 64$ & $85 \pm 24$ & $113 \pm 30$ & $97 \pm 22$ & $70 \pm 16$ & 0.317 \\
\hline Ethyl isovalerate $(\mu \mathrm{g} / \mathrm{L})$ & $14 \pm 6$ & $21 \pm 8$ & $22 \pm 10$ & $19 \pm 5$ & $24 \pm 6$ & $20 \pm 3$ & $12 \pm 4$ & 0.089 \\
\hline Isobutyl acetate $(\mu \mathrm{g} / \mathrm{L})$ & $81 \pm 50$ & $60 \pm 16$ & $94 \pm 34$ & $57 \pm 21$ & $84 \pm 32$ & $64 \pm 6$ & $85 \pm 37$ & 0.812 \\
\hline Isoamyl acetate $(\mu \mathrm{g} / \mathrm{L})$ & $2630 \pm 1859$ & $2009 \pm 726$ & $1919 \pm 209$ & $1556 \pm 778$ & $3690 \pm 2796$ & $1214 \pm 618$ & $2704 \pm 1620$ & 0.511 \\
\hline Hexyl acetate $(\mu \mathrm{g} / \mathrm{L})$ & $523 \pm 2581$ & $305 \pm 167$ & $262 \pm 90$ & $250 \pm 84$ & $301 \pm 285$ & $158 \pm 97$ & $325 \pm 130$ & 0.102 \\
\hline Diethyl succinate $(\mu \mathrm{g} / \mathrm{L})$ & $1142 \pm 835$ & $1299 \pm 359$ & $2201 \pm 953$ & $1802 \pm 832$ & $1441 \pm 551$ & $1979 \pm 669$ & $1241 \pm 766$ & 0.351 \\
\hline \multicolumn{9}{|l|}{ Alcohols } \\
\hline 1-Hexanol ( $\mu \mathrm{g} / \mathrm{L})$ & $2533 \pm 603$ & $2506 \pm 634$ & $2506 \pm 202$ & $2363 \pm 738$ & $1524 \pm 662$ & $1723 \pm 271$ & $2100 \pm 689$ & 0.147 \\
\hline 3-Hexenol $(E)(\mu \mathrm{g} / \mathrm{L})$ & $92 \pm 20$ & $72 \pm 36$ & $85 \pm 36$ & $114 \pm 49$ & $91 \pm 39$ & $70 \pm 241$ & $47 \pm 34$ & 0.192 \\
\hline 3-Hexenol $(Z)(\mu \mathrm{g} / \mathrm{L})$ & $521 \pm 95^{\mathrm{h}, \mathrm{w}, \mathrm{a}, \mathrm{c}, \mathrm{f}, \mathrm{u}}$ & $356 \pm 185^{c}$ & $266 \pm 109$ & $383 \pm 78^{\mathrm{c}, \mathrm{u}}$ & $165 \pm 47^{f}$ & $332 \pm 31$ & $202 \pm 27$ & $<0.0001$ \\
\hline Isobutanol (mg/L) & $15 \pm 1 \mathrm{w}, \mathrm{f}$ & $16 \pm 1^{\dagger}$ & $21 \pm 8$ & $18 \pm 4^{f}$ & $19 \pm 2.6^{f}$ & $27 \pm 11$ u & $16 \pm 2$ & 0.004 \\
\hline Isoamylalcohol (mg/L) & $201 \pm 171^{w, c, f}$ & $219 \pm 18$ & $238 \pm 63$ & $229 \pm 20$ & $259 \pm 5.8^{u}$ & $251 \pm 13$ & $211 \pm 6.2$ & 0.009 \\
\hline Phenylethanol (mg/L) & $23 \pm 11$ & $23 \pm 10$ & $28 \pm 13$ & $38 \pm 36$ & $23 \pm 2$ & $18 \pm 2$ & $18 \pm 2$ & 0.659 \\
\hline Methionol $(\mu \mathrm{g} / \mathrm{L})$ & $534 \pm 94$ & $529 \pm 87$ & $607 \pm 242$ & $567 \pm 87$ & $728 \pm 245$ & $563 \pm 55$ & $632 \pm 185$ & 0.482 \\
\hline \multicolumn{9}{|l|}{ Thiols } \\
\hline $3 M H A(n g / L)$ & $395 \pm 631^{\mathrm{h}, \mathrm{w}, \mathrm{a}, \mathrm{f}}$ & $74 \pm 83$ & $35 \pm 28$ & $37 \pm 19$ & $146 \pm 124^{f}$ & $10 \pm 11$ & $246 \pm 393$ & 0.007 \\
\hline $3 \mathrm{MH}(\mathrm{ng} / \mathrm{L})$ & $3786 \pm 1691^{\mathrm{a}, \mathrm{f}, \mathrm{u}}$ & $1532 \pm 929$ & $1184 \pm 334$ & $524 \pm 381$ & $2335 \pm 2111$ & $1151 \pm 776$ & $2033 \pm 2874$ & 0.013 \\
\hline $4 \mathrm{MMP}$ (ng/L) & $19 \pm 13$ & $13 \pm 4.6$ & $24 \pm 13$ & $8 \pm 4$ & $8 \pm 2$ & $11 \pm 10$ & $20 \pm 19$ & 0.143 \\
\hline \multicolumn{9}{|l|}{ Methoxypyrazines } \\
\hline MIBP (ng/L) & $27.2 \pm 9.3$ & $21.0 \pm-$ & $19.5 \pm 3$ & $27.6 \pm-$ & $16.4 \pm 2.8$ & - & $15.8 \pm 1.6$ & 0.809 \\
\hline
\end{tabular}

${ }^{*}$ Superscript letters $\left({ }^{m}=\right.$ Marlborough, ${ }^{h}=$ Hawkes Bay, ${ }^{w}=$ Wairarapa, ${ }^{a}=$ Australia, ${ }^{c}=$ Chile, ${ }^{\mathrm{f}}=$ France, ${ }^{\mathrm{u}}=$ United States) indicates the significant differences between countries and regions obtained using a pair-wise comparison (Tukey's HSD) with 95\% level of confidence. 
States wines were close together and separated from the other groups given their higher concentrations of 3-hexenol $(E)$ and lower levels of most other compounds. France was well separated from all of the other groups, most likely due to lower concentrations of 3MHA, 3-hexenol $(Z)$, and hexyl acetate. The third dimension explained a further $20 \%$ of the difference in the data set (Figure 3B) and clearly separated France, United States, and South Africa wines from Australia wines, which had higher concentrations of 3-hexenol (E), and MIPP. The $95 \%$ confidence intervals of the means for the Marlbor-
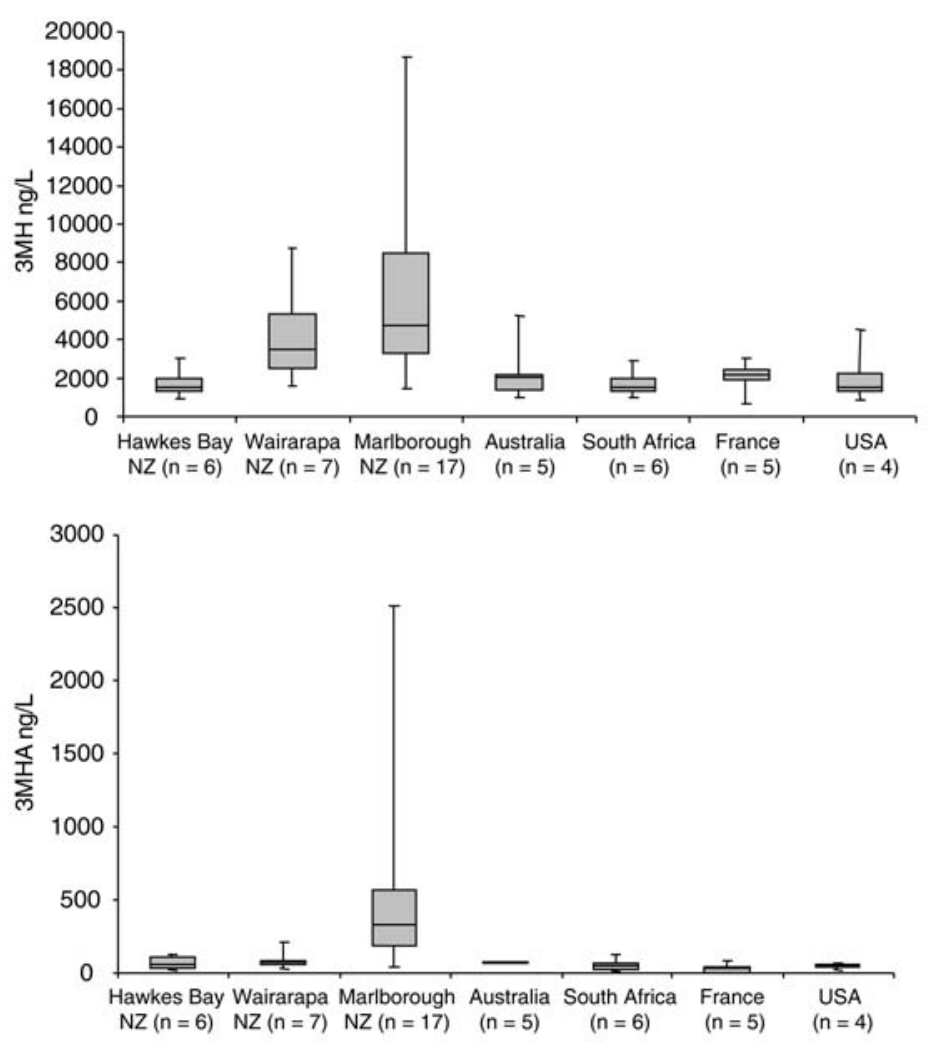

Figure 1 3-Mercaptohexanol (3MH) and 3-mercaptohexyl acetate (3MHA) in the Sauvignon blanc wines from the first set of samples: minima, lower quartile, median, upper quartile, and maxima.

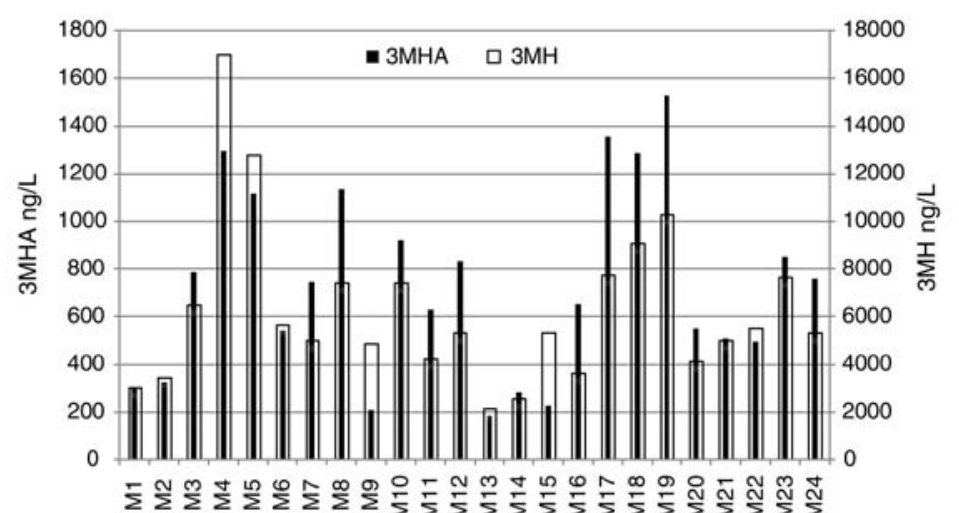

Figure 2 3-Mercaptohexanol (3MH) and 3-mercaptohexyl acetate (3MHA) concentrations in the commercial Marlborough Sauvignon blanc wines from the 2007 vintage. ough and Hawkes Bay regions were well separated due to 3MH, 3MHA, ethyl octanoate, ethyl decanoate, 1-hexanol, citronellol, 3-hexenol ( $Z$ ), and hexyl acetate.

Because the CVA technique assumes a normal distribution of the variables, which cannot be expected for our very diverse set of samples, the data set was also submitted to a classification tree analysis. This analysis obtained for the same data set (Figure 4) again discriminated the New Zealand wines from the international wines. The most powerful variable was $3 \mathrm{MHA}$, which separated the Marlborough and Wairarapa wines from all other wines. On the next level, 3-hexenol $(E)$ discriminated between the Marlborough and Wairarapa wines. Phenylethanol discriminated samples from the United States, South Africa, and Australia from the New Zealand and French wines. The French wines were well separated from the New Zealand wines, except for a few Wairarapa wines, due to lower concentrations of 3-hexenol $(Z)$ and
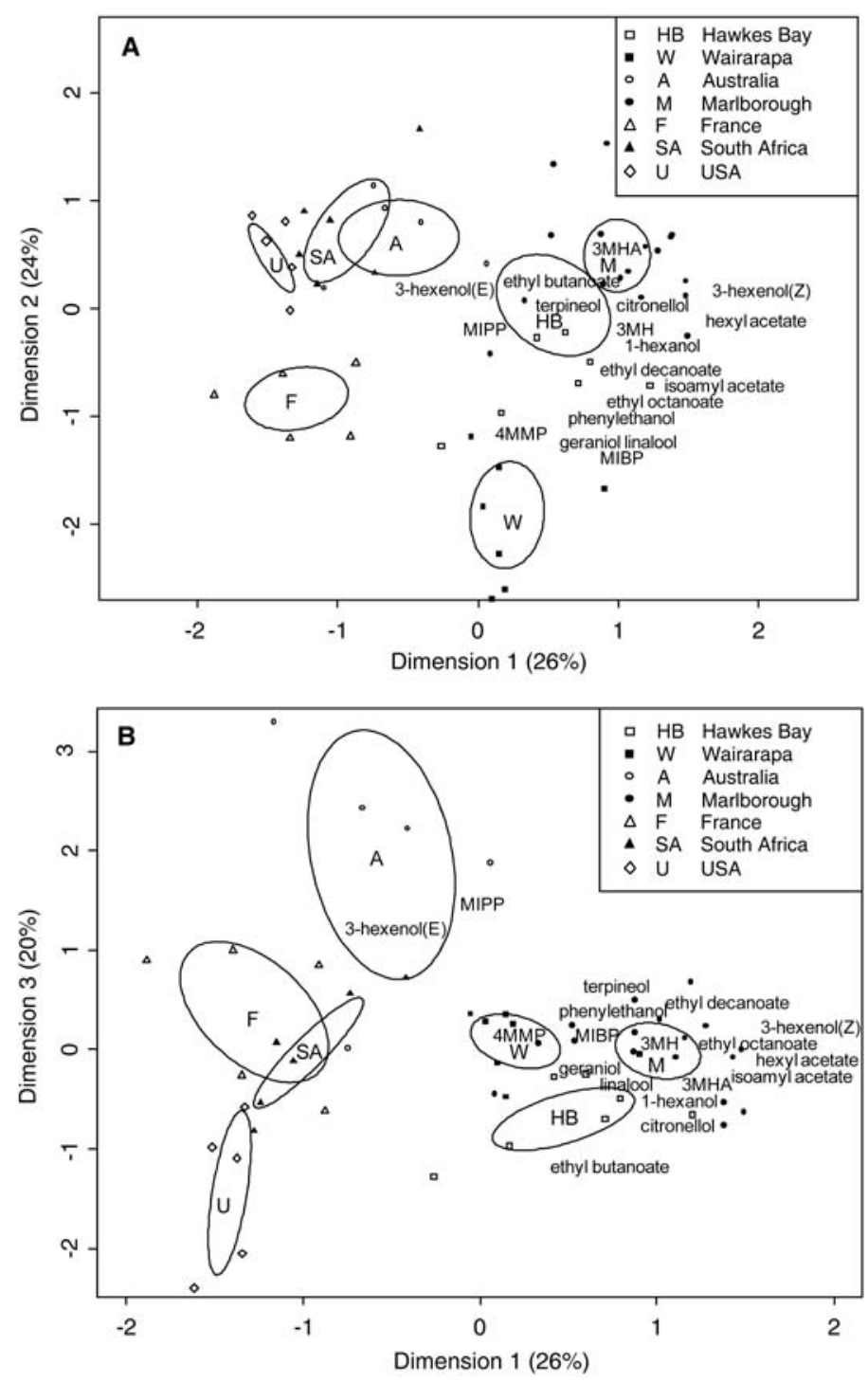

Figure 3 Regional differentiation of Sauvignon blanc wines from the first set of samples (2003 and 2004 vintages) by canonical variate analysis. Score and loadings plots of (A): first and second dimensions; (B): first and third dimensions. 
3MH. Some samples from Australia were classified closer to the New Zealand wines than to the other international wines, with MIPP and geraniol as the variables.

These results raise the issue of what impact the differences in the chemical composition among regions and countries may have on the sensory perception of these wines. Quantitative descriptive analysis of 16 descriptors was available for the first set of samples (2003 and 2004 vintage), as reported previously (Lund et al. 2009a). A partial least squares regression (PLSR) was presented using the chemical data for three volatile compounds (3MH, 3MHA, and MIBP) (X variables) and the sensory data ( $\mathrm{Y}$ variables) to determine correlations between chemical concentrations and sensory properties of the wines (Lund et al. 2009a). A second PLSR analysis of the previously published sensory data (Lund et al. 2009a) used a higher number of volatile compounds as $\mathrm{X}$ variables (Figure 5); 3MHA and 3MH showed correlations within the $95 \%$ confidence ellipse with their specific sensory descriptors: tropical, sweet sweaty passion fruit, and passion fruit skin stalk (Figure 5A). There were additional correlations among the chemical data between the two ethyl esters, ethyl octanoate and ethyl decanoate, and between the two acetates, hexyl acetate and isoamyl acetate. However, no other positive correlations between sensory and chemical data were observed within the $95 \%$ confidence ellipse.

Additional information concerning the impact of the chemical composition on the sensory perception of the wines was obtained from the score and $\mathrm{X}$ loadings (wines and chemical data) plot of the PLSR analysis (Figure 5B). For the CVA analysis, the discrimination between the New Zealand wines (right side of the plot, with a few exceptions) and the international wines (left side of the plot) is obvious and is due to higher concentrations of the chemicals quantified, except 3-hexenol $(E)$ in most of the New Zealand wines. The descriptors tropical, sweet sweaty passion fruit, pas-

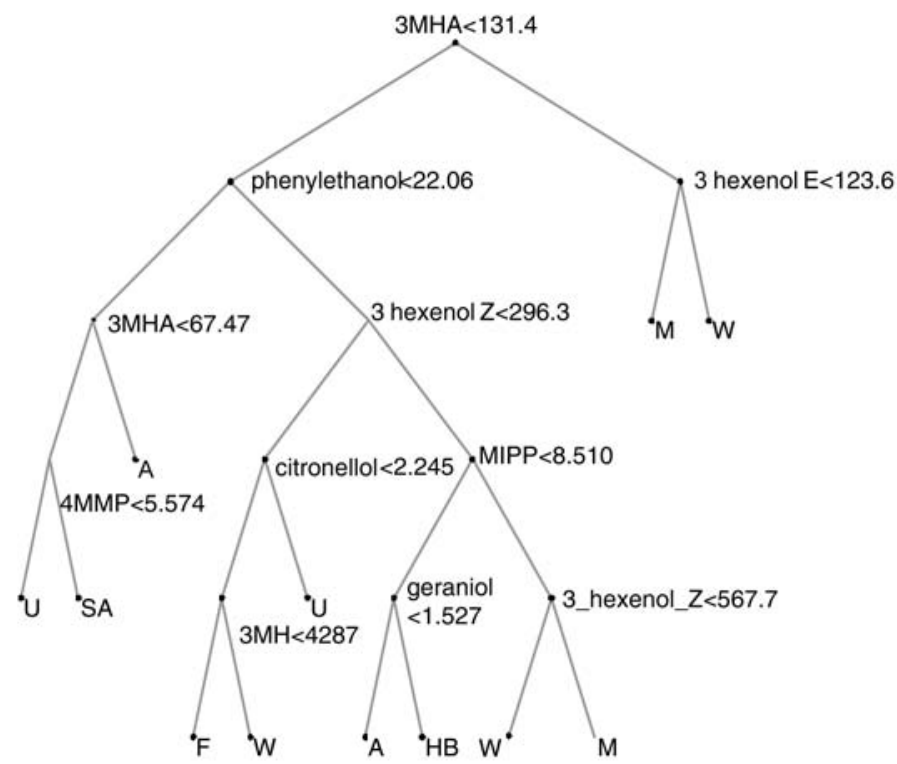

Figure 4 Classification tree of Sauvignon blanc wines from the first set of samples (2003 and 2004 vintages). sion fruit skin/stalk, stone fruit, cat urine, snow pea, fresh asparagus, citrus, mint, capsicum, and apple are grouped on the right side of the plot (Figure 5A) in the direction of the New Zealand wines, and higher concentrations of most of the aroma chemicals assigned to these characters were found in the New Zealand wines (Figure 5B). On the other hand, descriptors such as bourbon, flinty, canned asparagus, apple lolly, and grassy were more intense in the international wines and were grouped on the left side of the plot. Finally, the second dimension of the PLSR plot (Figure 5A, B) effectively discriminated a number of the Marlborough wines in the lower left quarter of the plot based on higher concentrations of 3MHA and 3MHA and higher intensities of the descriptors tropical, sweet sweaty passion fruit, and passion fruit skin stalk, together with other descriptors such as stone fruit, cat urine, snow pea, fresh asparagus, citrus, mint, and capsicum.

\section{Discussion}

Based on perception thresholds and odor activity values, past research has largely attributed the characteristic aroma of
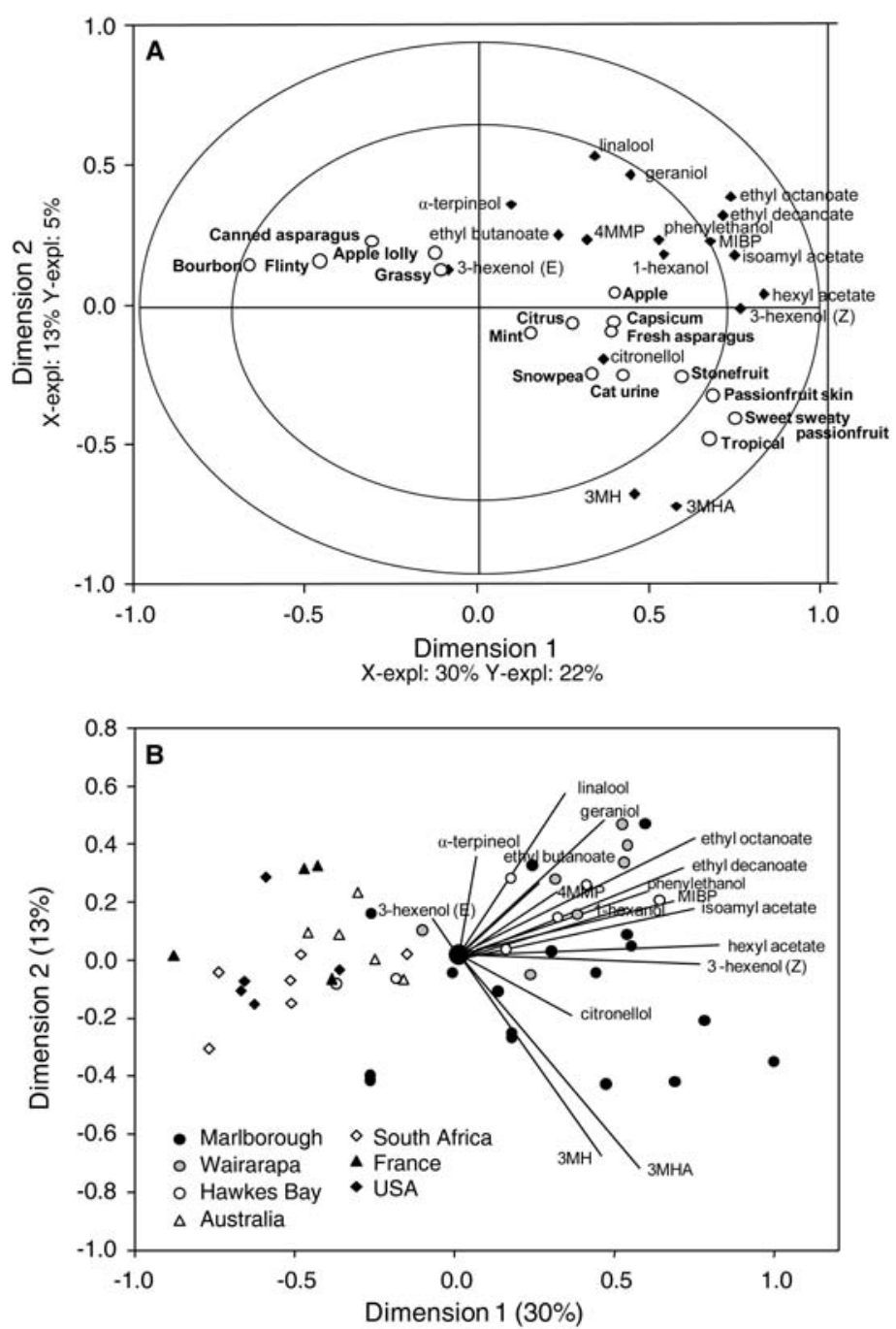

Figure 5 Correlations between aroma compounds and sensory properties of the Sauvignon blanc wines from the first set of samples (2003 and 2004 vintages) by partial least squares regression analysis. (A): first and second dimensions of the loadings $(X=$ chemical data; $Y=$ sensory data); (B): score and $\mathrm{X}$ loadings (wines/chemical data). 
Sauvignon blanc wines to a few aroma compounds, represented by the polyfunctional mercaptans and methoxypyrazines (Tominaga et al. 1998a, 2006, Augustyn et al. 1982, Allen et al. 1991, Lacey et al. 1991, Marais 1994). However, the use of perception thresholds is questionable because of the use of synthetic matrices instead of wine matrices for threshold determinations. Moreover, recent research approaches, such as aroma reconstitution (Escudero et al. 2004, 2007, Campo et al. 2005, Ferreira et al. 2006, Pineau et al. 2007), indicate that wine aroma is influenced by complex interactions between various wine components and is rarely dominated by a single component. In order to understand what chemicals contribute to the distinct aroma characteristics of Marlborough Sauvignon blanc wine, this study has taken a holistic approach to Sauvignon blanc wine aroma by quantifying an important number of volatile compounds in wines over two vintages. Among the 20 volatile compounds quantified (Table 4), several compounds other than the polyfunctional mercaptans and methoxypyrazines were shown to be present in concentrations above their sensory perception thresholds (Table 2). In particular, several fermentative esters - isoamyl acetate, ethyl butanoate, ethyl hexanoate, ethyl isovalerate, and ethyl isobutyrate-exceeded perception thresholds. Other esters such as hexyl acetate, ethyl octanoate, and ethyl decanoate were very close to their reported perception thresholds. With fruity, flowery, and sweet characters, esters are known to be particularly important in the generation of the bouquet of young white wines and interact with an additive effect (van der Merwe and van Wyk 1981, Campo et al. 2005). Moreover, the esters contributed to the separation of New Zealand wines from the international wines (Figure 3, Figure 5) in the first, but not the second, set of samples. More importantly, there was a positive relationship between concentrations of higher esters and a higher intensity of the fruity, capsicum, and fresh asparagus descriptors and a negative relationship with a higher intensity of the descriptors bourbon, flinty, and canned asparagus (Figure 5). The green, grassy-like higher alcohols, 1-hexanol and 3-hexenol $(Z)$, were also present at levels close to or above their perception thresholds (Table 2). These two compounds also contributed to the discrimination between most of the New Zealand and the international wines (Figure 3). Moreover, 3-hexenol $(Z)$ was also involved in separating the New Zealand and some Australia wines from the other wines in the classification tree analysis (Figure 4). Despite quantification at concentrations close to or just under their perception thresholds (Table 2), the higher alcohols and monoterpenes contributed to the regional discrimination of the wines (Figure 3, Figure 5), with phenylethanol as the second most powerful variable that separated the wines using the classification tree analysis. The varietal methoxypyrazines, especially MIBP, were present at concentrations well above their perception thresholds, and they contributed to the regional discrimination of the first set of wines (vintage 2003 and 2004). However, as reported previously (Lund et al. 2009a), MIBP did not exhibit a direct correlation with the capsicum descriptor (Figure 5), but was involved in a negative relationship with the intensity rating of the bourbon character.
A masking or suppressing effect between alkyl methoxypyrazines and 3MHA (Campo et al. 2005) and white wine polyphenols (Lund et al. 2009b) has been reported already and could also explain these results.

Finally, for all wines, the varietal polyfunctional mercaptans were present at concentrations well above their perception thresholds (Table 2). Moreover, 3MH (passion fruit skin/ stalk) and 3MHA (sweet sweaty passion fruit) were typically present at higher concentrations in the wines from the Marlborough region, together with some wines from Wairarapa (first set of samples), United States, and Chile (second set of samples). The importance of 3MHA and $3 \mathrm{MH}$ for the discrimination of Marlborough wines was confirmed by the classification tree (Figure 4) and CVA (Figure 3) approaches. The Marlborough wines also showed a high degree of variability in $3 \mathrm{MH}$ and $3 \mathrm{MHA}$ concentrations (Figure 1, Figure 2), which were the only compounds that correlated well with their sensory descriptors, as demonstrated by PLSR analysis (Figure 5). Compared to $3 \mathrm{MH}$ and 3MHA, the boxwood/cat urine-like 4MMP displayed a different trend, with a much lower variation within and between regions. Likewise, 4MMP played a less important role in discriminating the Marlborough wines. A strong correlation could not be obtained between 4MMP and the cat urine or any other sensory descriptor.

Wine sensory profiles and/or wine chemical composition have been successfully and extensively used to investigate geographical influences on wines made from several grape varieties, such as Riesling (Douglas et al. 2001), Chardonnay (Schlosser et al. 2005), Albarino (Vilanova and Vilarino 2006), Pinot noir (Cliff and Dever 1996), and Sauvignon blanc (Berna et al. 2009). This study is the first to consider and successfully demonstrate the implication of a comprehensive number of wine volatile compounds in the geographic discrimination of Sauvignon blanc wines. Our results confirmed the clear role for $3 \mathrm{MH}$ and $3 \mathrm{MHA}$ in the aroma of Sauvignon blanc wines and in the discrimination of wines. However, both CVA (Figure 3) and PLSR analyses (Figure 5 ) indicate the contribution of several other compounds to Sauvignon blanc aroma. The discrimination of New Zealand wines from the international wines was based on a number of compounds that also included methoxypyrazines, 4MMP, fermentative esters, $\mathrm{C}_{6}$-alcohols, phenylethanol, and monoterpenes. While the regional differences obtained in this study will be influenced by the inevitable bottling time differences between the two hemispheres, differences in winemaking practices, and an unbalanced sampling in favor of the Marlborough region, the overall trend of wine chemical and sensory data separation is still apparent and is strongly supported by the PLSR analysis (Figure 5). This analysis separated the wines by differences in the concentrations of volatile compounds and in the complex sensory profiles, with higher intensities of the tropical, sweet sweaty passion fruit, passion fruit skin/stalk, stone fruit, cat urine, snow pea, fresh asparagus, capsicum, apple, citrus, and mint in the Marlborough wines. On the other hand, the wines that had lower concentrations of most of the volatile compounds were also characterized by a different sensory profile, with lower 
intensities of the descriptors listed above, and were instead dominated by bourbon, flinty, canned asparagus, apple lolly, and grassy-like descriptors. Notably, the wines that were well separated due to higher intensities of the tropical, sweet sweaty passion fruit, and passion fruit skin/stalk descriptors were all Marlborough wines that had exceptionally high concentrations of $3 \mathrm{MH}(>5000 \mathrm{ng} / \mathrm{L})$ and $3 \mathrm{MHA}(>500 \mathrm{ng} / \mathrm{L})$. Additional Marlborough wine profiles were evident, but they were more difficult to define and seem to be influenced by more volatile compounds. This result is not surprising, as Marlborough Sauvignon blanc wines are known to exhibit different styles ranging from a grassy, crispy end to a more tropical, fruity style. This important intraregional variation can be associated with great differences in $3 \mathrm{MH}$ and $3 \mathrm{MHA}$ concentrations (Figure 1, Figure 2). Further research on the composition of Marlborough Sauvignon blanc using wines obtained under a controlled manner (similar grape pressing conditions and standardized winemaking) may help to understand this variation in $3 \mathrm{MH}$ and $3 \mathrm{MHA}$ concentrations.

Several studies have used PLSR to demonstrate correlations between wine volatile compounds and sensory characteristics (Noble and Ebeler 2002, Aznar et al. 2003). The PLRS analysis was helpful for this study in establishing several relationships between the sensory and chemical data together with the importance of $3 \mathrm{MH}$ and $3 \mathrm{MHA}$ to the aroma of certain Marlborough Sauvignon blanc wines. However, the correlations obtained were too weak to be used for Sauvignon blanc aroma predictive models, despite intensive training of the sensory panelists with chemical references and specifically selected descriptors (Lund et al. 2009a). Therefore, this study demonstrates the limitation of this approach when the chemical compounds are considered for their contribution to wine aroma quality. Existing statistical tools that allow the correlation of chemical and sensory data to be examined, such as PLRS, are based on linear regression models and therefore cannot take into consideration a nonlinear relationship between sensory descriptors and chemical compounds (Guichard 1995, Meilgaard 2006), changes of the sensory descriptor or sensory descriptor intensity related to the chemical concentration of a specific compound, and/or any interaction with other compounds from the wine matrix (Murat et al. 2001, Campo et al. 2005, Escudero et al. 2007, Pineau et al. 2007, Lund et al. 2009b). From the point of view of the results obtained in the present study, there is a clear need for a deeper understanding of Sauvignon blanc wine aroma complexity through methodologies such as aroma reconstitution, designed to confirm the specific role of individual compounds in different wine matrices. These research methodologies can be used the confirm the role of different concentrations of $3 \mathrm{MH}$ and 3MHA in Sauvignon blanc wine profiles and to understand the contribution of $\mathrm{C}_{6}$-alcohols, fermentative esters, methoxypyrazines, phenylethanol, and monoterpenes to the overall aroma of Sauvignon blanc wines.

\section{Conclusions}

The quantification of numerous volatile compounds in Sauvignon blanc wines from New Zealand and several in- ternational producers over several vintages showed the importance of polyfunctional mercaptans, methoxypyrazines, and fermentative esters and $\mathrm{C}_{6}$-alcohols for wine aroma. Multivariate statistical analysis was able to discriminate New Zealand wines from most of the international wines, based on the concentrations of polyfunctional mercaptans, $\mathrm{C}_{6}$-alcohols, fermentative esters, methoxypyrazines, phenylethanol, and some monoterpenes. When the sensory data was considered through a PLS analysis, higher amounts of these volatile compounds could explain the more complex aroma profiles dominated by higher intensities of the tropical, sweet sweaty passion fruit, passion fruit skin/stalk, stone fruit, cat urine, snow pea, fresh asparagus, capsicum, apple, citrus, and mint descriptors. The role of the polyfunctional mercaptans, $3 \mathrm{MHA}$ and $3 \mathrm{MH}$, in the distinctive tropical, fruity character of Marlborough Sauvignon blanc wine was strongly demonstrated. Moreover, a high concentration of these compounds was also characteristic of the Marlborough wines, although here again the contribution of the other volatile compounds needs to be considered. A more complete understanding of Sauvignon blanc chemical composition and aroma reconstitution is the focus of our future research to elucidate the contribution of the different chemicals involved in the overall aroma profiles of this distinctive wine.

\section{Literature Cited}

Allen, M.S., M.J. Lacey, R.L.N. Harris, and W.V. Brown. 1991. Contribution of methoxypyrazines to Sauvignon blanc wine aroma. Am. J. Enol. Vitic. 42:109-112.

Augustyn, O.P.H., A. Rapp, and C.J. Van Wyk. 1982. Some volatile aroma components of Vitis vinifera L. cv. Sauvignon blanc. S. Afr. J. Enol. Vitic. 3:53-60.

Aznar, M., R. Lopez, J. Cacho, and V. Ferreira. 2003. Prediction of aged red wine aroma properties from aroma. J. Agric. Food. Chem. 51:2700-2707.

Berna, A.Z., S. Trowell, D. Clifford, W. Cynkar, and D. Cozzolino. 2009. Geographical origin of Sauvignon blanc wines predicted by mass spectrometry and metal oxide based electronic nose. Anal. Chem. Acta 648:146-152.

Campo, E., V. Ferreira, A. Escudero, and J. Cacho. 2005. Prediction of the wine sensory properties related to grape variety from dynamicheadspace gas chromatography-olfactometry data. J. Agric. Food Chem. 53:5682-5690.

Cliff, M.A., and M.C. Dever. 1996. Sensory and compositional profiles of British Columbia Chardonnay and Pinot Noir wines. Food Res. Int. 29:317-323.

Douglas, D., M.A. Cliff, and A.G. Reynolds. 2001. Canadian terroir: Characterization of Riesling wines from Niagara Peninsula. Food Res. Int. 34:559-563.

Escudero, A., B. Gogorza, M.A. Melus, N. Ortin, J. Cacho, and V. Ferreira. 2004. Characterization of the aroma of a wine from Maccabeo. Key role played by compounds with low odor activity values. J. Agric. Food Chem. 52:3516-3524.

Escudero, A., E. Campo, L. Farina, J. Cacho, and V. Ferreira. 2007. Analytical characterization of the aroma of five premium red wines. Insights into the role of odor families and the concept of fruitiness of wines. J. Agric. Food. Chem. 55:4501-4510.

Ferreira, V., A. Rapp, J.F. Cacho, H. Hastrich, and I. Yavas. 1993. Fast and quantitative determination of wine flavor compounds using microextraction with Freon 113. J. Agric. Food Chem. 41:1413-1420. 
Ferreira, V., R. López, and J.F. Cacho. 2000. Quantitative determination of the odorants of young red wines from different grape varieties. J. Sci. Food Agric. 80:1659-1667.

Ferreira, V., N. Ortín, A. Escudero, R. López, and J. Cacho. 2002. Chemical characterization of the aroma of Grenache rosé wines: Aroma extract dilution analysis, quantitative determination, and sensory reconstitution studies. J. Agric. Food Chem. 50:4048-4054.

Ferreira, V., A. Pet'ka, and J. Cacho. 2006. Intensity and persistence profiles of flavor compounds in synthetic solutions. Simple model for explaining the intensity and persistence of their aftersmell. J. Agric. Food Chem. 54:489-496.

Francis, I.L., M.A. Sefton, and P.J. Williams. 1992. Sensory descriptive analysis of the aroma of hydrolysed precursor fractions from Semillon, Chardonnay and Sauvignon blanc grape juice. J. Sci. Food Agric. 59:511-520.

Guichard, H., E. Guichard, D. Langlois, S. Issanchou, and N. Abbott. 1995. GC sniffing analysis: Olfactive intensity measurement by two methods. Z. Lebensm.-Unters.-Forsch. 201:344-350.

Guth, H. 1997. Quantitation and sensory studies of character impact odorants of different white wine varieties. J. Agric. Food Chem. 45:3027-3032

Hebditch, K.R., L. Nicolau, and M.A. Brimble. 2007. Synthesis of isotopically labelled thiol volatiles and cysteine conjugates for quantification of Sauvignon blanc wine. J. Label. Compd. Radiopharm. 50:237-243.

Kotseridis, Y., R.L. Baumes, A. Bertrand, and G.K. Skouroumounis. 1999. Quantitative determination of 2-methoxy-3-isobutylpyrazine in red wines and grapes of Bordeaux using a stable isotope dilution assay. J. Chromatogr., A 841:229-237.

Lacey, M.J., M.S. Allen, R.L.N. Harris, and W.V. Brown. 1991. Methoxypyrazines in Sauvignon blanc grapes and wines. Am. J. Enol. Vitic. 42:103-108.

Lee, S.J. 2003. Finding key odorants in foods: Gas chromatography olfactometry (GC/O). Food Sci. Biotechnol. 12:597-602.

Lund, C.M., M.K. Thompson, F. Benkwitz, M.W. Wohler, C.M. Triggs, R. Gardner, H. Heymann, and L. Nicolau. 2009a. New Zealand Sauvignon blanc distinct flavor characteristics: Sensory, chemical, and consumer aspects. Am. J. Enol. Vitic. 60:1-12.

Lund, C.M., L. Nicolau, R. Gardner, and P.A. Kilmartin. 2009b. Effect of polyphenols on the perception of key aroma compounds from Sauvignon blanc wine. Aust. J Grape Wine Res. 15:18-26.

Marais, J. 1994. Sauvignon blanc cultivar aroma-A review. S. Afr. J. Enol. Vitic. 15:41-45.

Meilgaard, M.C., G.V. Civille, and B.T. Carr. 2006. Sensory Evaluation Techniques. 4th ed. CRC Press, Boca Raton, FL.

Murat, M.L, I. Masneuf, P. Darriet, V. Lavigne, T. Tominaga, and D. Dubourdieu. 2001. Effect of Saccharomyces cerevisiae yeast strains on the liberation of volatile thiols in Sauvignon blanc wine. Am. J. Enol. Vitic. 52:136-139.
Nicolau, L., F. Benkwitz, M. Maggu, N.I. Ellett, P. Butler, T. Tominaga, M.C.T. Trought, and P.A. Kilmartin. 2008. New Zealand Sauvignon blanc-Revealing and protecting its unique aroma characteristics. In Proceedings of the Thirteenth Australian Wine Industry Technical Conference. R. Blair et al. (eds.), pp. 197-204. Glen Osmond, Australia.

Noble, A.C., and S.E. Ebeler. 2002. Use of multivariante statistics in understanding wine flavor. Food Rev. Int. 18:1-21.

Parr, W.V., J.A. Green, K.G. White, and R.R. Sherlock. 2007. The distinctive flavour of New Zealand Sauvignon blanc: Sensory characterisation by wine professionals. Food Qual. Pref. 18:849-861.

Pineau, B., J.C. Barbe, C. Van Leeuwen, and D. Dubourdieu. 2007. Which impact for $\beta$-damascenone on red wines aroma? J. Agric. Food Chem. 55:4103-4108.

Ribéreau-Gayon, P., Y. Glories, A. Maujean, and D. Dubourdieu. 2001. Handbook of Enology. Vol. 2. The Chemistry of Wine Stabilization and Treatment. Wiley \& Sons, Chichester, UK.

Rychlik, M., P. Schieberle, and W. Grosch. 1998. Compilation of Odor Thresholds, Odor Qualities and Retention Indices of Key Food Odorants. Lichtenbergstraße, Germany.

Sabon, I., G. De Revel, Y. Kotseridis, and A. Bertrand. 2002. Determination of volatile compounds in Grenache wines in relation with different terroirs in the Rhone Valley. J. Agric. Food Chem. 50:6341-6345.

Schlosser, J., A.G. Reynolds, M. King, and M. Cliff. 2005. Canadian terroir: Sensory characterization of Chardonnay in the Niagara Peninsula. Food Res. Int. 38:11-18.

Sefton, M.A., I.L. Francis, and P.J. Williams. 1994. Free and bound volatile secondary metabolites of Vitis vinifera grape cv. Sauvignon blanc. J. Food Sci. 59:142-147.

Tominaga, T., A. Furrer, R. Henry, and D. Dubourdieu. 1998a. Identification of new volatile thiols in the aroma of Vitis vinifera $\mathrm{L}$. var. Sauvignon blanc wines. Flav. Fragrance J. 13:159-162.

Tominaga, T., M.L. Murat, and D. Dubourdieu. 1998b. Development of a method for analyzing the volatile thiols involved in the characteristic aroma of wines made from Vitis vinifera L. cv. Sauvignon blanc. J. Agric. Food Chem. 46:1044-1048.

Tominaga, T., Y. Niclass, E. Frérot, and D. Dubourdieu. 2006. Stereoisomeric distribution of 3-mercaptohexan-1-ol and 3-mercaptohexyl acetate in dry and sweet white wines made from Vitis vinifera (var. Sauvignon blanc and Semillon). J. Agric. Food Chem. 54:7251-7255.

van der Merwe, C.A., and C.J. van Wyk. 1981. The contribution of some fermentation products to the odor of dry white wines. Am. J. Enol. Vitic. 32:41-46.

Vilanova, M., and F. Vilarino. 2006. Influence of geographical origin on aromatic descriptors of Spanish Albarino wines. Flav. Fragrance J. 21:373-378 